\title{
A gestão do talento em idade escolar: o caso das «sociedades criativas»
}

\section{The management of school-age talent: the case of 'creative societies'}

\author{
Isabel Garcez \\ Universidade de Lisboa
}

\begin{abstract}
Resumo
A arte e a cultura compreendem as necessidades globais da sociedade. Portanto, o potencial socioeconómico das indústrias culturais e criativas e das suas classes laborais é considerável. O talento é cada vez mais parte integrante das competências dos trabalhadores do futuro e a sua gestão deverá iniciar-se desde o início da idade escolar. O talento começa sempre como um diamante em bruto que é preciso lapidar, sendo que desta lapidação depende muito do seu valor futuro. Estas ações de lapidação deverão pautar-se por uma deontologia adequada por partes de todos, a começar pela comunidade escolar.

Palavras-chave: talento, educação, sociedades criativas.
\end{abstract}

\begin{abstract}
Art and culture understand the global needs of society. Therefore, the socio-economic potential of the cultural and creative industries and their working classes is considerable. Talent is increasingly an integral part of the skills of the workers of the future and their management should start from the beginning of school age. Talent always begins as a rough diamond that needs to be lapidated, and this stoning depends largely on its future value. These actions of stoning should be guided by an appropriate deontology by parts of all, starting with the school community.

Keywords: talent, education, creative societies.
\end{abstract}

As indústrias culturais e criativas alteram estilos de vida através de novas «sementes da curiosidade» (Livro Verde, 2010: 6) e potenciam uma relação íntima com a cultura ao longo da vida, pelo que será salutar «uma colaboração mais intensa, sistemática e abrangente entre as artes e as instituições académicas e científicas (Livro Verde, 2010: 6).

É neste quadro que os mediadores culturais, nomeadamente, os professores, ganham especial relevo, pois deles se espera que contribuam para que os seus educandos se tornem cidadãos com «padrões de excelência a nível mundial.» (Livro Verde, 2010: 7).

Para uma sociedade criativa, como a nossa, é essencial atrair talentos capazes de manter o fluxo do processo criativo, e esses talentos são os criadores propriamente ditos, que garantem as novas ideias e as novas obras, mas são também talentos criativos que suportam esses criadores e os acompanham nas fases de produção, divulgação, comercialização e receção da respetiva obra, entre os quais, temos os chamados mediadores.
Uma sociedade criativa carece igualmente de decisores políticos que compreendam as especificidades e as potencialidades de cada um dos seus subsetores, com particular destaque para as indústrias culturais e criativas.

O papel destes decisores pode ser, por exemplo, harmonizar a formação académica e técnica e as práticas profissionais, proporcionando um tipo de aprendizagem que dê acesso não só a informação atualizada mas também a experiências concretas. Este formato educativo é o mais importante adequado a um mercado composto maioritariamente por pequenas ou médias empresas, nas quais a qualidade da formação teórica e técnica dos seus colaboradores deve ser acompanhada de um bom nível de polivalência e capacidade de adaptação aos cenários sempre imprevisíveis da criação de bens culturais e criativos.

A política de coesão da União Europeia reconheceu o contributo da cultura para a concretização dos seus objetivos estratégicos, tais como a convergência, a competitividade e o emprego. Estas estratégias integradas de desenvolvimento devem ser definidas, preferencialmente, no quadro de parcerias entre as «entidades públicas responsáveis pelas diferentes políticas (como sejam o desenvolvimento económico, o emprego, a educação e a cultura) e os representantes da sociedade civil, ou seja, as empresas, os trabalhadores e as associações de cidadãos» (Livro Verde, 2010: 11).

Uma sociedade criativa é complexa e repleta de subtis mas determinantes relações de causa-efeito, pelo que o seu sucesso está dependente de a União Europeia e dos governos nacionais e regionais reconhecerem e apoiarem o papel da cultura num paradigma de desenvolvimento que não se limita às fronteiras europeias. Imprescindíveis intercâmbios culturais, num contexto local, global ou glocal, são o reflexo dos valores comuns que estão no centro do projeto europeu.

Um aspeto muito importante das sociedades criativas é a sua natural apetência para elaborar leituras abrangentes do mundo. A arte e a cultura, a par da ciência, são as atividades que mais rapidamente compreendem as necessidades globais da humanidade e, promovendo as adequadas mudanças de comportamentos e atitudes. São estas atividades que melhor respondem aos grandes desafios civilizacionais, sejam eles o aquecimento global ou os conflitos étnicos e/ou religiosos, pois o facto de 
fomentarem e abraçarem grandes causas torna-as parceiros insubstituíveis no momento de esclarecer as mentes e as ações das pessoas comuns.

É preciso, no entanto, relembrar que cultura e educação são totalmente interdependentes. Uma não existe sem a outra e nem uma nem outra são suficientes, se separadas, para enfrentar o devir das sociedades. A cultura que não está apoiada numa base de largo espectro da educação limita-se a afetar uma minoria e a fomentar diferenças sociais que demoram gerações a ser ultrapassadas. A educação que não está direcionada para elevar os níveis de cultura dos seus educandos limita-se a formar cidadãos dóceis e sem curiosidade, com ambições imediatistas e pouco diversificadas. Portanto a solução consiste em maximizar a relação entre a cultura e a educação, com base num pressuposto principal: «todas as pessoas são criativas, de uma forma ou de outra, e podem aprender a utilizar o seu potencial criativo» (Livro Verde, 2010: 19).

Está bem de ver que consideramos a cultura e a educação, em geral, e as indústrias culturais e criativas, em particular, como macromediadores institucionais e empresariais, profundamente dependentes das decisões e das ações de cada uma das pessoas que os constituem.

Se, por um lado, temos um contexto aparentemente favorável àquilo que podemos apelidar de empatia sociocultural, em que se parte do princípio de que as indústrias culturais e criativas são benéficas aos cidadãos e à sociedade, por outro lado, a sociedade atual é ainda marcadamente neoliberal, na qual, sem «sombra de dúvida, a vontade do capitalista consiste em encher os bolsos o mais que possa.» (Marx, 1996. Vol. I: 73)

Já não é possível continuar a ver a arte e a cultura como setores exclusivamente subsidiados, devido à sua natureza não económica e não lucrativa porque o seu valor económico é cada vez mais reconhecido. As indústrias culturais e criativas são, assim, um sistema complexo que combina talento, inovação, ideias, competências, tecnologia, gestão e processos de produção, reconhecimento e valorização. Principalmente no atual contexto económico, que é a «combination of factors of production, tangible and intangible» (The Economy of Culture, 2006: 39).

O Relatório das Nações Unidas de Economia Criativa (2012) apresenta a perspetiva deste organismo sobre as sociedades criativas e sobre o valor das indústrias culturais e criativas no desenvolvimento global e glocal. O relatório indica, por exemplo, que o comércio de produtos e serviços criativos permaneceu relativamente sólido, mesmo num momento em que os níveis gerais caíram, devido à crise financeira mundial de 2008, defendendo que «embora o crescimento da economia criativa não seja, por si só, uma panaceia, ele potencialmente oferece caminhos mais resilientes, inclusivos e sustentáveis» (Relatório das Nações Unidas, 2012: 17).

Não é, portanto, de estranhar que tanto países desenvolvidos como em desenvolvimento estejam a dedicar uma atenção cada vez maior às indústrias culturais e criativas, até porque estas, devido às suas características intrínsecas promovem uma «abordagem mais holística ao desenvolvimento» (Relatório das
Nações Unidas, 2012: 22). Esta abordagem holística caracteriza-se por ser inclusiva e eclética e desempenha um papel essencial num quadro económico pautado pela complexidade e pela incerteza, como é o das indústrias culturais e criativas. Será também essa abordagem holística que justificará o facto de «em 2008, apesar dos $12 \%$ de queda vivenciados pelo comércio global, o comércio mundial de produtos e serviços criativos continuou sua expansão, [...] refletindo uma taxa de crescimento anual de 14\%» (Relatório das Nações Unidas, 2012: 22).

Estes valores representam uma nova tendência de consumo que é, à primeira vista, muito positiva, mas é preciso compreender as suas perversidades. Quando se junta o consumo generalizado de bens culturais com a industrialização da arte e da cultura, estamos a abrir portas à criação de produtos que só na sua aparência são culturais. Na sua essência, são apenas produtos criativos, cujo contributo para um alargamento do conhecimento e da informação dos consumidores é, também ele, apenas aparente.

A originalidade dos produtos culturais está na base do seu valor no mercado e significa «criar algo a partir no nada ou reconstruir algo que já exista.» (Relatório das Nações Unidas, 2012: 34). Portanto, o conceito de produtos culturais caracteriza-se por ser um produto que resulta da criatividade humana, um veículo de mensagens simbólicas não utilitário e cuja propriedade intelectual é atribuída ao indivíduo ou grupo que o produz. Estes atores constituem a classe criativa e esta «inclui pessoas que fazem parte dos campos da ciência e engenharia, arquitetura e design, educação, artes, música e entretenimento» (Relatório das Nações Unidas, 2012: 48). A classe criativa é assim constituída por um grupo bastante heterogéneo de trabalhadores, que se caracteriza pela sua criatividade, individualidade, diferença e mérito. Nesta classe criativa podem ainda ser incluídos os empreendedores criativos, capazes de transformar ideias em produtos ou serviços criativos para a sociedade e que são «uma força motriz na economia do conhecimento» (Relatório das Nações Unidas, 2012: 50).

A economia criativa está de boa saúde e é por isso uma economia que gera emprego. $\mathrm{O}$ desafio é considerar as classes criativas que a compõem uma parte integrante da estratégia das próprias empresas e não como quadros superiores meramente executivos, pois o que se pretende é levar as pessoas a realizar o seu potencial, o que «significa saber gerir os recursos humanos com inteligência, sensibilidade e flexibilidade» (Santos, 2004: 148).

Numa sociedade em que as indústrias criativas representam uma parte cada vez mais significativa da economia, os quadros altamente qualificados tornam-se o potencial estratégico das indústrias culturais e criativas. Estes quadros têm um alto grau de criatividade, uma capacidade de aprendizagem permanente e uma fácil adaptação a novos meios tecnológicos e deles dependem as ideias e as soluções de qualidade para criar ou seguir as tendências que alimentam a indústria.

As novas classes laborais das indústrias culturais e criativas são, portanto, técnicos, cientistas, artistas ou, idealmente, uma mistura de todos em diferentes 
percentagens, consoante as necessidades do momento. Só assim é possível manter e desenvolver um tecido empresarial caracterizado por um forte dinamismo económico, social e cultural. São pessoas cuja função económica e cultural é a gestação permanente de novas ideias para a criação e desenvolvimento de novos produtos. Todos estes produtos se caracterizam por dependerem de conteúdos criativos, sejam eles um novo tecido e um novo tipo de papel, ou a camisola e o livro fabricados com um e com o outro.

Convém realçar que não há uma única definição para economia criativa, pois é um conceito ainda subjetivo e em desenvolvimento. Economia criativa é um conceito emergente baseado na ideia de capital criativo, muito embora a criatividade na economia não seja uma ideia absolutamente nova, pois o consumo sempre dependeu de novos produtos que respondem a velhas necessidades ou criam novas. O que é novo na economia criativa é a relação entre os diferentes agentes e a forma como todos estão obrigados a criar valor diferenciado que se reflita em riqueza. Se este valor diferenciado é facilmente contabilizado nos produtos, através do volume de vendas, o mesmo não acontece quanto à diferenciação das capacidades artísticas dos criadores ou das competências criativas dos diferentes elementos da cadeia de produção. Aqui o valor de cada um resulta de uma amálgama qualitativa de propriedades, tais como a originalidade e a experiência, sendo muito difícil de quantificar o valor da contribuição de cada elemento em cada fase da vida do produto.

$\mathrm{O}$ meio cultural apresenta-se em «concentric circles, surrounded by "cultural periphery" and "creative industries"»(Peters e Araya, 2010: xiii). Isto significa que os bens culturais, mesmo os que acabam por se revelar grandes sucessos comerciais, entram no mercado através de franjas periféricas que orbitam o núcleo duro das indústrias culturais e criativas. Numa sociedade criativa altera-se a tradicional relação da arte com o mainstream económico ao afastá-la de uma posição unicamente periférica, como acontecia até há pouco. Recentemente, economistas e sociólogos passaram mesmo a ver as indústrias culturais e criativas «as either already or potentially central to contemporary economic life.» (Hesmondhalgh e Pratt, 2004: 11)

Esta nova abordagem tem uma profunda importância no papel da educação, tanto na formação de públicos e futuros consumidores de produtos oriundos das indústrias culturais e criativas como na formação de profissionais capazes de integrar as novas classes laborais que correspondam às novas exigências de uma sociedade criativa. Nas escolas, o papel das artes na formação das atitudes e comportamentos sociais das crianças é já bastante reconhecido. A educação e as instituições «são responsáveis por formar indivíduos [...] para se juntarem à mão-de-obra criativa $[. .$.$] e, no longo$ prazo, para construir uma população mais culturalmente consciente» (Relatório das Nações Unidas, 2012: 54).

Não existem indústrias culturais e criativas em sociedades com fracos níveis de alfabetização ou literacia, assim como também não existem em contextos com baixas performances socioeconómicas. Portanto, as indústrias culturais e criativas contribuem em muito para o desenvolvimento das sociedades em que existem. Além disso, este desenvolvimento tem bons níveis de sustentabilidade, sendo que atualmente o conceito de sustentabilidade é muito mais abrangente e deixou de ser aplicado em exclusivo ao meio ambiente. O capital cultural, material e imaterial de uma comunidade é algo que deve ser preservado para futuras gerações, da mesma forma que os recursos naturais e ecossistemas, e precisa de ser protegido da mesma forma para garantir a sobrevivência e evolução da humanidade.

Do ponto de vista da sustentabilidade, a criatividade é um recurso inato e abundante por todo o mundo e, como matéria-prima, é menos dependente de infraestruturas industriais e potencialmente menos poluente. Por isso, a criatividade pode ser facilmente compatível com os valores mais nobres de uma sociedade, promovendo o desenvolvimento e elevando os níveis socioeconómicos com menores impactes no meio ambiente.

Neste contexto, a gestão de talentos defende que é dos criadores que provém a matéria-prima que poderá ser transformada em material pelos diversos quadros criativos institucionais ou empresariais. Em última instância, serão sempre os talentos a promover o crescimento económico destas indústrias e respetivas sociedades. Se uma das definiçõoes de indústrias culturais e criativas, e uma das nossas preferidas, é a defendida por Maria de Lourdes Lima dos Santos (2005: 17) que entende as indústrias culturais e criativas como «aquelas atividades industriais que integram trabalho cultural ou artístico diretamente nos seus produtos», não podemos perseguir políticas que entendem os criadores e criativos como meros fornecedores (naturalmente, sem desprimor para estes).

A admiração que todos os intervenientes deverão ter pelos criadores revê-se totalmente nestas palavras de Christian Bourgois: «Sempre tive grande consideração pela criação artística, seja ela literária ou outra, e, por conseguinte, pelos criadores. O talento de um político ou de um empresário, e conheci vários muito brilhantes e famosos, por maior que seja nunca me impressionou tanto como a energia de um artista» (Bourgois, 2013: 54).

Ao gestor de talentos compete ser capaz de minimizar os efeitos nocivos e de maximizar os efeitos positivos da realidade em que os talentos com que trabalha estão inseridos. Para todos os que lidam diariamente com talentos, a consciência de que qualquer gesto influencia o sistema como um todo é uma constante e dela decorre uma inegável responsabilidade. Tomando as palavras de Carmen Tojo (2011: 87), gerir talentos implica sempre a presença de fatores internos e externos. Entre os fatores internos, destacam-se o medo do fracasso ou do êxito, o perfeccionismo ou uma deturpada autoimagem. Quanto aos fatores externos, sobressaem as pressões resultantes das expectativas, o que implica apelar a bons níveis de autocontrolo e autoconhecimento, pois são estes os fatores determinantes para obter uma boa performance e alcançar ambiciosos objetivos. Estas pessoas com capacidades especiais, materializadas no seu talento artístico, terão de ter um acompanhamento compatível. Portanto, o seu gestor será muitas vezes a família ou os amigos, o psicólogo, o treinador ou o professor. 
É sabido que não basta ter talento para ter sucesso. $\mathrm{O}$ talento começa sempre como um diamante em bruto que é preciso lapidar, dependendo da lapidação muito do valor que terá no fim do processo. Assim, ao lapidador/gestor de talento/professor é pedido que saiba reconhecer o valor intrínseco da pedra mas também as condições de lapidação que apresenta.

Numa economia do conhecimento, como é a nossa, os talentos precisam de ambientes de trabalho de excelência, isto é, ambientes que se adaptem ao seu ritmo de trabalho e às necessidades particulares que cada uma das suas obras exige. Procuram também, inevitavelmente, contextos que lhes possibilitam oportunidades de crescimento e recompensas adequadas. O sucesso só se torna uma realidade quando há a adequação de esforços e competências às necessidades particulares dos talentos. Neste sentido, o sucesso de um talento apenas se revela quando existem as competências, a motivação e a visão corretas entre os que com ele trabalham.

Podemos comparar esta gestão de talentos ao tipo de acompanhamento a dar a um aluno sobredotado nas medidas educativas previstas para tal. Num e noutro contextos, questões como «(i) aceleração escolar, (ii) programas de enriquecimento e (iii) agrupamento dos alunos com tais caraterísticas» (Window e Salgado, 2013: 3063) encontram eco nas competências reservadas ao gestor de talentos. Também este deverá apresentar objetivos cada vez mais exigentes e ambiciosos, suscitar novas linhas de ação e de incentivar o jogo de espelhos com a obra dos seus pares, possibilitando diagnosticar fraquezas ou sedimentar forças. É preciso, no entanto, ter em consideração que «não existe uma única fórmula que possa ser usada com eficácia para todos» (Window e Salgado, 2013: 3064). Assim, é tarefa do gestor encontrar as formas adequadas a cada um dos talentos com quem trabalha.

Ao longo das últimas décadas, o ritmo das transformações sociais e económicas tem produzido alterações significativas nas sociedades, nas culturas e nos mercados. Estamos num contexto em que tanto a informação (e não tanto o conhecimento, como seria preferível) como a criação e a criatividade se transformaram em mais-valias comerciais. Isto leva a que talentos (criação) e respetivos gestores (criatividade) estejam a tornar-se recursos cada vez mais limitados, o que não significa que estes recursos estejam a ser devidamente valorizados. $\mathrm{O}$ gestor de talentos precisa de conquistar uma posição adequada no meio em que funciona, tanto perante os talentos que gere como perante os organigramas em que se insere.

O trabalho de um gestor de talentos é necessariamente o trabalho de um líder - como também pode ser o trabalho de um treinador, de um professor, de um psicólogo, ou até de um familiar ou de um amigo que funcione como uma figura de autoridade. E esse líder sabe que a sua liderança tem exatamente o tamanho da satisfação do talento e da equipa com quem trabalha. A sua principal vitória é servir e possibilitar que uma dada obra de arte tenha impacte considerável no modo como os seus recetores veem o mundo. Uma obra de arte pode enriquecer a perspetiva que cada pessoa tem do mundo, mas pode igualmente, através e a partir dela, desenvolver novos artistas, novos talentos que virão a renovar e/ou a substituir os já existentes. Uma vitória é sempre um motivo de satisfação, mas também implica uma responsabilidade maior. Uma vitória implica sempre a consciência da possibilidade de uma derrota e uma derrota implica sempre a necessidade de mudar.

Um gestor de talentos só é capaz de concretizar os seus propósitos, se tiver em mente que o seu trabalho se depara continuamente com incógnitas e que as soluções encontradas terão se ser flexíveis mas resilientes. Um gestor de talentos tem de lidar, e ajudar o seu talento a lidar, com uma delicada teia de equilíbrios cujos fios são oriundos de fontes muito diversas e nem sempre visíveis.

A arte é, desde os seus primórdios, o que liberta o Homem das vias únicas, o que dá profundidade a uma paisagem social já conhecida, o que renova caminhos velhos e constrói novos. Nela, e na sociedade que a enquadra, a posição destinada a um gestor de talentos é particularmente discreta, e, segundo o nosso entender, assim deve ser.

Segundo Pierre Bourdieu, a responsabilidade de um mediador cultural (no caso, um gestor de talentos) é também histórica porque «toda a transformação da estrutura do campo acarreta uma trasladação da estrutura dos gostos, ou seja, do sistema das distinções simbólicas entre os grupos (Bourdieu, 2010: 184).

É esta a importância e é esta a responsabilidade social que atribuímos à arte, ao artista e ao mediador cultural/gestor de talentos. Ao gestor-modelo de hoje tem de lhe ser exigida «uma formação cultural, científica, ética e deontológica acima da média e uma forte personalidade que lhe permitam resistir de modo positivo ao crescendo de pressões que passaram a exercer-se sobre a sua ação» (Araújo, 2009: 95).

Não é fácil ser-se gestor de talentos, até porque persiste a ideia de que os dotes da criação, e também os da criatividade, são inatos e que, portanto, implicam pouco ou nenhum esforço. Assim sendo, a nota positiva com que temos de procurar fechar todos os nossos dias laborais e todos os contactos que temos com os criadores/talentos, reflete-se em Gianni Rodari e na sua Gramática da Fantasia (2006: 196), quando defende que uma sociedade não deve assentar apenas na realidade do lucro, nem formar «meios-homens - fiéis executores, diligentes reprodutores, dóceis instrumentos sem vontade».

Defendemos que as características de um talento são bastante aproximadas das de um sobredotado, pois, passado o tempo em que a sobredotação era apenas associada a quocientes de inteligência elevados, atualmente as definições apontam (apenas) para alguém que apresenta uma elevada «capacidade intelectual geral; aptidão académica específica; pensamento criativo e produtivo» (Window e Salgado, 2013: 3059).

No que respeita à criatividade, colocamos as mesmas questões de Todd Lubart (2007: 9): «Até que ponto a criatividade depende de um nível elevado de inteligência, de traços específicos de personalidade, ou ainda, da natureza do contexto?». E concordamos com as suas conclusões: «a criatividade é o resultado de uma convergência de fatores cognitivos, conativos [estilo, 
motivação] e ambientais» (Lubart, 2007: 15). A criatividade é algo inerente ao Homem e os processos criativos não se restringem à arte. Consideramos, no entanto, que a criatividade se identifica com um agir integrado no quotidiano, enquanto a criação implicará entendimentos mais profundos desse agir criativo que não se restringem aos desafios desse quotidiano, antes os constroem através da revelação de mundos ainda não vividos.

Ao contrário do que muitos seguidores do atualíssimo coaching parecem fazer crer, a criatividade continua a ser muito diferente da criação, embora exista muitas vezes essa confusão no seio das indústrias culturais e das sociedades criativas. A criação é a ideia primeira que nasce, exclusiva, na mente do seu criador, e a criatividade não está, como muitas vezes se tenta fazer crer, ao mesmo nível. Numa analogia com o mundo do desporto, diremos que a criatividade e a criação jogam em campeonatos diferentes e, em muitos casos, pertencem mesmo a modalidades diferentes. No entanto, a importância da criatividade é grande, principalmente nas indústrias criativas, nas quais se movimentam. Aos criativos é pedido que saibam orientar-se pela experiência e pelos modelos previamente testados, dado que «sem modelos orientadores, muitas vezes prevalece a insegurança» (Araújo, 2009: 91).

É sabido que a existência de um talento «resulta da relação entre fatores endógenos e exógenos» (Araújo, 2009: 71). No caso dos talentos artísticos, os fatores endógenos contemplarão, por exemplo, a concretização artística que resulta numa determinada forma. Os fatores exógenos poderão ser uma prática artística multifacetada desde as idades mais jovens e o correspondente envolvimento social, ético e pedagógico em que decorre essa prática.

Portanto, ao mediador cultural, ao gestor de talentos, ao professor compete assumir a sua quota-parte de responsabilidade na formação de públicos, nomeadamente de públicos novos capazes de descodificar e apreender formas de arte nova. Compete-lhe igualmente contribuir para que a democracia da criação e a democratização da receção se tornem uma realidade.

Ser um mediador cultural implica assumir uma intransmissível responsabilidade social que se caracteriza por um espetro muito alargado de ações e de atitudes. Ser mediador cultural, no geral, e professor, no particular, significa ser alguém que se vê a si próprio além das suas obrigações enquanto quadro técnico superior. É por este motivo que consideramos ser chegado o momento de os mediadores culturais assumirem a tomada de consciência do seu papel imprescindível na sociedade.

\section{Referências}

Araújo, Jorge (2009). Ser Treinador. Alfragide: Texto. Bourdieu, Pierre (2010). As Regras da Arte. Génese e estrutura do campo literário. São Paulo: Companhia das Letras. Trad. Maria Lucia Machado.

Bourgois, Christian (2013). «O futuro do livro continua a ser o livro». Lisboa: Ler, jan. Trad. Sofia Gomes.
Hesmondhalgh, David e Pratt, Andy C. (2004). «Cultural industries and cultural policy». International Journal of Cultural Policy, n. ${ }^{\circ} 11$. Londres.

Livro Verde. Realizar o potencial das indústrias culturais e criativas (2010). Bruxelas: Comissão Europeia

(https://infoeuropa.eurocid.pt/registo/000044774/)

Marx, Karl (1996). O Capital. S. Paulo: Editora Nova Cultural. Trad. Regis Barbosa e Flávio R. Kothe. Vol. I.

Lubart, Todd (2007). Psicologia da Criatividade. Porto Alegre: Artmed. Trad. Márcia Conceição.

Peters, Michael A. e Araya, Daniel (coord.) (2010). Education in the creative economy knowledge and learning in the age of innovation. Londres: Peter Lang.

Relatório das Nações Unidas de Economia Criativa 2010: Economia criativa, uma opção de desenvolvimento (2012). Brasília: Secretaria da Economia Criativa.

Rodari, Gianni (2006). Gramática da Fantasia. Introdução à arte de inventar histórias. Lisboa: Caminho. Trad. José Colaço Barreiros.

Santos, Maria de Lourdes Lima dos (coord.) (2005). Contribuições para a Formulação de Políticas Públicas no Horizonte 2013 Relativas ao Tema Cultura, Identidades e Património. Lisboa: Instituto de Ciências Sociais da Universidade de Lisboa e Observatório das Atividades Culturais.

The Economy of Culture in Europe (2006). Bruxelas: Comissão Europeia.

(http://ec.europa.eu/assets/eac/culture/library/studies/c ultural-economy_en.pdf)

Tojo, Carmen María Pomar. 2011. «Una perspectiva integral de la superdotación»

(https://www.aneis.org/wp-content/uploads/2016/08/sob redotacao_v12-2011.pdf)

Window, Pedro e Salgado, Ana M. (2013). «Papel do professor na identificação e acompanhamento de crianças sobredotadas». Atas do XII Congresso Internacional Galego-Português de Psicopedagogia. Braga: Universidade do Minho

(http://webs.ie.uminho.pt/xiigp/capa.pdf) 